\title{
The Pattern of Thalassemia in Children at the Department of Child Health, School of Medicine University of North Sumatera/ Dr. Pirngadi Hospital, Medan
}

\author{
by
}

SUGIANI SINULINGGA, ISMET FADIL LOEBIS AND ADI SUTJIPTO

(From The Department of Child Health, School of Medicine University of North Sumatera/Dr. Pirngadi Hospital, Medan)

\begin{abstract}
A study of the characteristics of childhood thalassemia was conducted at the Sub Department of Pediatric Hematology, Dr. Pirngadi Hospital from June 1979 to May 1989.

There were 131 cases, consisting of $75(57.25 \%)$ boys and $56(42.75 \%)$ girls with an average of 12 admission every year. The predominant age group was 0-2 years, and the youngest was 3 months old. Javanese ethnic group appeared predominant in 36 (63.15\%) cases.

Clinical symptoms of anemia were found in 112 (85.49\%), hepatomegaly in 91 (69.46\%), hepatosplenomegaly in $84(64.12 \%)$, without enlargement of organ in 17 $(12.97 \%)$, and icterus in $6(4.58 \%)$. Hb-Electrophoresis was done in 42 cases, revealing 26 (61.90\%) with thalassemia major, 15 (35.71\%) Hb E thalassemia, and 1 (2.20\%) $\mathrm{Hb} \mathrm{H}$ thalassemia. $\mathrm{Hb}$ value at the first admission in $65(49.62 \%)$ was less than $5 \mathrm{~g} / \mathrm{dl}$, in $63(48.09 \%)$ it was $5-10 \mathrm{~g} / \mathrm{dl}$ and in $3(2.29 \%)$ more than $10 \mathrm{~g} / \mathrm{dl}$.
\end{abstract}




\section{Introduction}

Thalassemia is a form of an inherited hemolytic anemia. It is inherited from both mother and father according to Mendel's law, and is caused by hemoglobin synthesis disorders $(1,2)$. This disease is seen not only in the surrounding of the Mediterranian Sea but also in Asean countries, including Indonesia (3)

The clinical manifestations vary from the most severe thalassemia mayor to the asymptomatic thalassemia minor. In general, clinical manifestation of thalassemia mayor appears at the age of 6 months

\section{Materials and methods}

This study was done retrospectively by collecting and analyzing all medical records of patients with thalassemia admitted to the Sub Department of Pediatric Hematology, Department of Child Health, School of Medicine, University of North Sumatera Dr. Pirngadi Hospital Medan from June 1979 to May 1989.

The data collected consisted of age, sex, parents race, main complaints, laboratory findings, results of $\mathrm{Hb}$-electrophoresis, bone marrow picture and body-weight.

The diagnosis was based on anamnesi (allo anamnesis), physical examination,

peripheral blood, bone marrow and nutritional status of the patients. The nutritional Kartu Menuju Sehat (Road to Health Chart) was used while for those more than 5 years old, the Harvard's International Standard (1959) was used. Patients with body weight of $80 \%$ of the 50th percentile were classified as normal (wellnourished), 60-80 \% as mild and moderate and less
Hematology, Department of Child Health,

chool of Medicine, University of North

Sumatera/Dr. Pirngadi Hospital Medan. status was determined by body weight for age.

For children under five years old the than $60 \%$ as severe malnutrition.

abnormal physical development for age, thalassemia and $1(2.2 \%) \mathrm{Hb}-\mathrm{H}$ thalassemia (Figure 2)

In 131 patients, $121(85.49 \%)$ were admitted with symptomatic anemia, 107 $(81.68 \%)$ with splenomegaly, 91 (69.47\%) with hepatomegaly, $6(4.58 \%)$ with icterus and $6(4.58 \%)$. with the other complaints (Table 2).

Sixty five patients $(49.62 \%)$ had $\mathrm{Hb}$ levels of less than $5 \mathrm{~g} / \mathrm{dl}, 63(48.09 \%) 5-10$

Table 1 : Distribution of patients by age and sex

\begin{tabular}{|c|c|c|c|}
\hline \multirow{2}{*}{ Age (years) } & \multicolumn{2}{|c|}{ Se $x$} & \multirow{2}{*}{ Number of patients } \\
\hline & Male & Female & \\
\hline $0-2$ & 24 & 23 & 47 \\
\hline 4 & 17 & 9 & 26 \\
\hline 6 & 11 & 9 & 20 \\
\hline 8 & 9 & 9 & 18 \\
\hline 10 & 3 & 4 & 7 \\
\hline 12 & 6 & - & 6 \\
\hline 14 & 3 & 2 & 5 \\
\hline 16 & 2 & - & 2 \\
\hline Tot a 1 & 75 & 56 & 131 \\
\hline
\end{tabular}

$\mathrm{g} / \mathrm{dl}$, and only $3(2.2 \%)$ more than $10 \mathrm{~g} / \mathrm{dl}$ (Table 3).

Out of 131 patients, nutritional evaluation were only done in 123 patients revealing $21(17.07 \%)$ wellnourished and $102(82.93 \%)$ malnourished (moderate and poor) children (Table 4 ).

The average of admission per years was 12 cases. The member of admission by sex is shown in Figure 1.

\section{Results}

From June 1979 to May 1989, 131 pa- can be seen in Table 1.

tients $(75=57.25 \%)$ boys and $56=$ The average of admission per years was $42.75 \%$ girls) were admitted. Most of the 12 cases. The number of admission by sex cases were found in the age group of $0-2$ is shown in Fig. 1.

years ( 47 cases $=35.87 \%$ ) and it seemed that the older the child, the less was the number of cases found. The youngest patient was 3 months old and the oldest 14 years. Distribution of sex by the age group

Thirty six of 57 cases $(63.15 \%)$ have a Javanese father as well as mother. Forty seven cases had the electrophoretic hemoglobin level showing $26(61: 91 \%)$, thalassemia mayor $15(33.71 \%)$. Hb E 


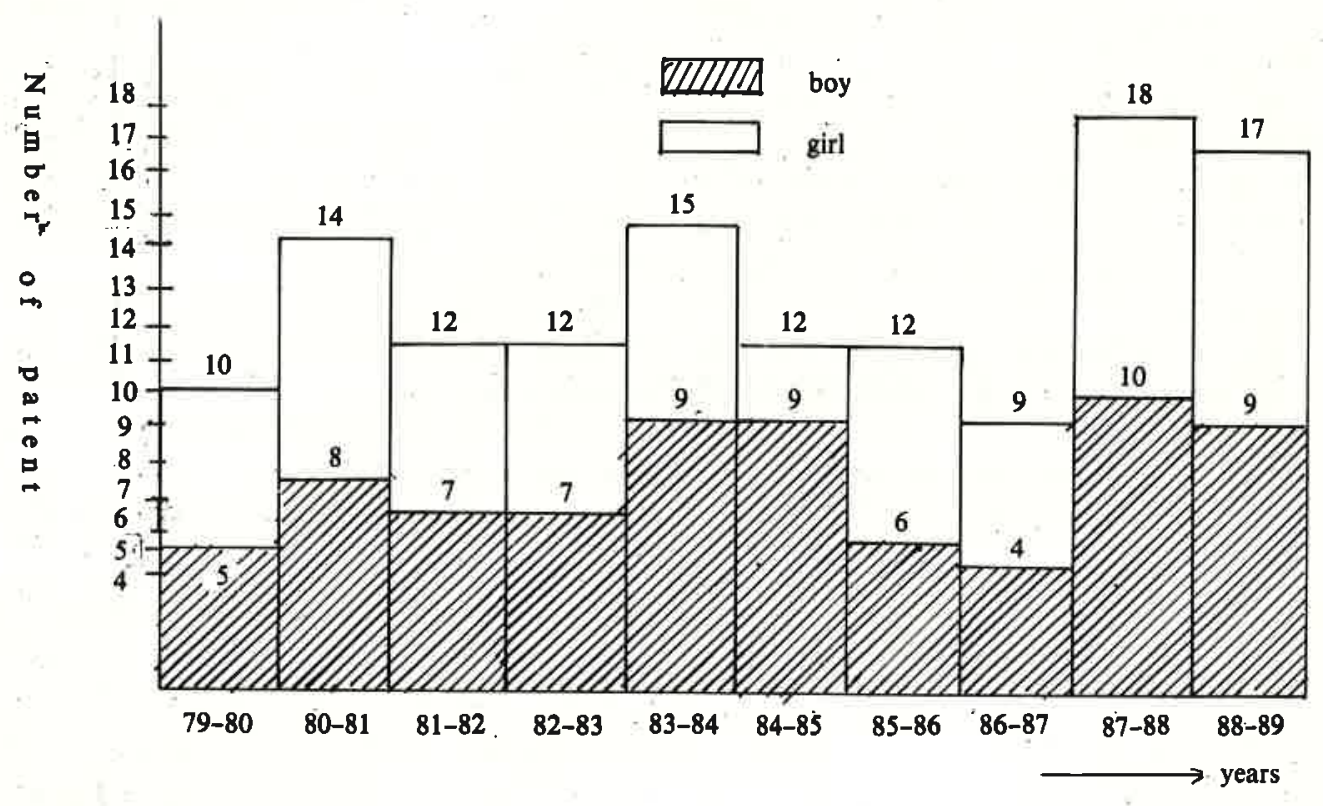

Figure 1 : Number of patients per-year according to sex

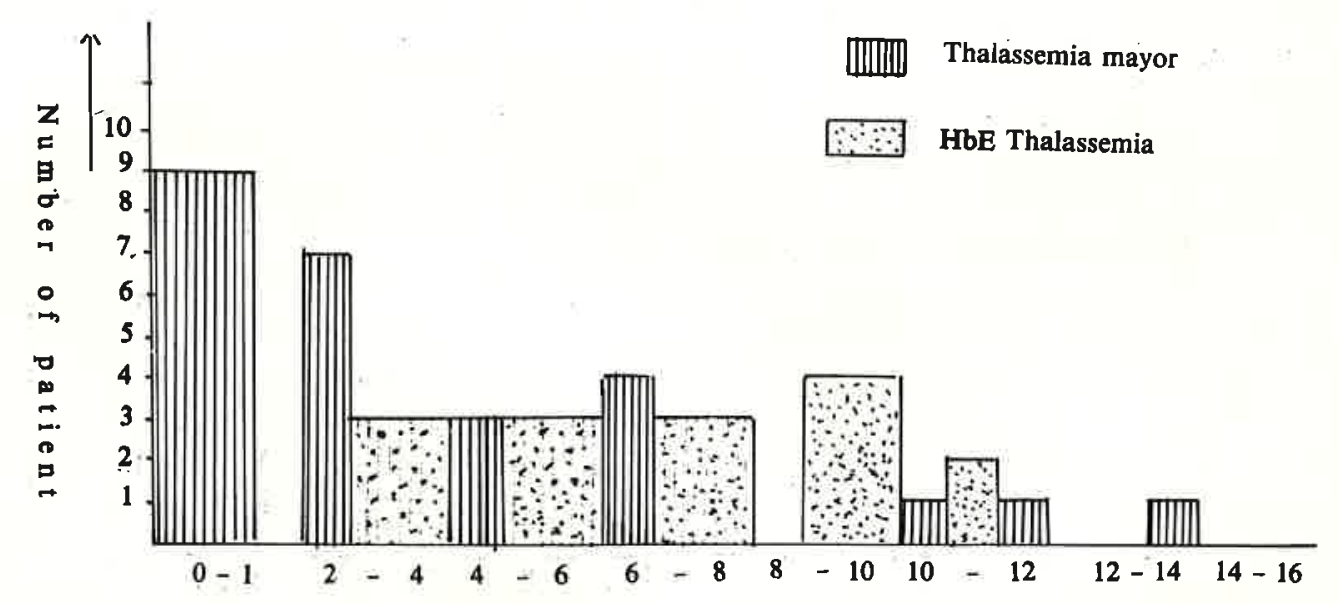

Figure $2:$ Number of patient with major thalassemia, $\mathrm{Hb} \mathrm{E}$ thalassemia according to age group
Table 2: Clinical manifestation

\begin{tabular}{|lcc|}
\hline Symptom / Sign & Number & $\%$ \\
\hline Anemia & 112 & 85.49 \\
Splenomegaly & 107 & 81.68 \\
Hepatomegaly & 91 & 69.47 \\
Icterus & 6 & 4.58 \\
Others & 6 & 4.58 \\
\hline
\end{tabular}

Table 3 : Hb Level

\begin{tabular}{|lcc|}
\hline Hb Level (g/dl) & Number & $\%$ \\
\hline Less than 5 & 65 & 49.62 \\
$5-10$ & 63 & 48.09 \\
More than 10 & 3 & 2.2 \\
\hline T o t al & 131 & 100.00 \\
\hline
\end{tabular}

Table 4 : Nutritional status by age group

\begin{tabular}{|rrrrrrrr|}
\hline \multirow{5}{*}{ Age (years) } & \multicolumn{5}{c|}{ Nutrtional Status } \\
\cline { 2 - 6 } & \multicolumn{2}{c}{ Good } & \multicolumn{2}{c|}{ Moderate } & \multicolumn{2}{c|}{ Poor } \\
\hline $0-1$ & 8 & $34.78 \%$ & 15 & $65.22 \%$ & 0 & $0 \%$ & 23 \\
-3 & 3 & $9.67 \%$ & 19 & $61.29 \%$ & 9 & $29.04 \%$ & 31 \\
-5 & 6 & $27.27 \%$ & 10 & $43.48 \%$ & 7 & $20.25 \%$ & 23 \\
-10 & 4 & $12.12 \%$ & 23 & $69.69 \%$ & 6 & $18.19 \%$ & 33 \\
10 & 0 & $0 \%$ & 4 & $30.77 \%$ & 9 & $69.23 \%$ & 13 \\
\hline T o t a 1 & 21 & $17.07 \%$ & 71 & $57.72 \%$ & 31 & $25.21 \%$ & 123 \\
\hline
\end{tabular}




\section{Discussion}

From June 1979 to May 1989, one hundred and thirty one patients were admitted $(75=57.25 \%$ boys and $56=42.75 \%)$ girls). Iskandar (1979) found thalassemia in $58.2 \%$ boys and $41.8 \%$ girls.

Patients with thalassemia were predominantly found in the age group of $0-2$ years $(47=37.8 \%)$, this is similar with the report of some authors who stating that thalassemia occurred in the age group of 6 to 12 years at the time when the management of physiological anemia was unsuccessful.

In this study, the youngest patient was 3 months old when the electrophoretic $\mathrm{Hb}$ examination indicated the manifestation of thalassemia mayor. Iskandar also found the youngest patient to be 3 months old.

There was no increase in the number of admissions per year, with the average of 12 cases annually. Of 57 patients, it was found that $36(63.15 \%)$ patients had a Javanese mother as well as father, while the rest were of various ethnic groups of North Sumatera. The predominance of the Javanese ethnic group needs further studies.

Electrophoretic $\mathrm{Hb}$ examination was done only in 42 cases showing $26(61.90 \%)$, thalassemia major, $15(35.71 \%) \mathrm{Hb} \mathrm{E}$

\section{Conclusions}

Of 131 patients with thalassemia in this study, $75(57.25 \%)$ were boys and 56 $(42.75 \%)$ girls. Most of these patients were found in the age group of $0-2$ years. The youngest patients was 3 months old. Most of the cases are of the Javanese ethnic group. The symptoms of thalassemia thalassemia and $1(2.2 \%) \mathrm{Hb} \mathrm{H}$ thalassemia. It was found that thalassemia mayor occurred in the age group of $0-2$ years (9 cases $=100 \%$ ), and the number of patients with thalassemia mayor decreased with the increase of age. $\mathrm{Hb} \mathrm{E}$ thalassemia occurred in the age group of older than two years. This might be caused by more severe course of thalassemia mayor $\mathrm{Hb}$ E thalasemia.

Anemia was found predominantly as a symptom at the first time of admission. This was found both in thalassemia mayor and thalassemia minor. In this study, 112 $(83.49 \%)$ had anemia, $107(81.68 \%)$ slenomegaly, $91(69.47 \%)$ hepatomegaly, and 17 case showed no organomegaly at all.

The enlargement of organs is caused by the activities of extra medullary erythropoetic system and iron overloading of the organs. It might suppress the abdomen, especially the digestive tract; the child might lose its appetite and then it tends to the disturbances of nutritional status and growth.

In this study, only $21(17.07 \%)$ were in good nutritional status, while $102(82.93 \%)$ had malnutrition.

\section{REFERENCES}

1. NIENHUIS AW. Propper PD. The Thalassemia 3. GITHAUS JH, HATHAWAY EW. Hematology In : Nathan DG, eds. Hematology of infancy and disorder. In: Kempe, eds. Current pediatric childhood. Philadelphia : WB Saunders, 1975 : 726-787.

2. PERASON HA. Thalasemia In: Behrman RE, 4. ISKANDAR W. T7. eds. Nelson Textbook of pediatrics. Philadelphia: sity of Indonesia, 1979. Disertation. WB Saunders, 1987: 1052-1Q54.

mayor might occurr in the group of younger than 2 years. The main clinical manifestation in these cases were anemia, splenomegaly and hepatomegaly. Patients might have no enlargement of organs. Generally, patients were admitted with malnutrition. 